\title{
Modelling Micro-climate Characteristics for Urban Planning and Building Design
}

\author{
Wolfgang Loibl, Tanja Tötzer, Mario Köstl, Hans Züger, and Markus Knoflacher \\ AIT Austrian Institute of Technology GmbH, Foresight and Policy Development Department, \\ A-1220 Donau-City-Strasse 1, Vienna, Austria \\ \{Wolfgang.Loibl, Tanja.Toetzer, Mario.Koestl, Johann. Zueger, \\ Markus.Knoflacher\} eait.ac .at
}

\begin{abstract}
Climate sensitive urban planning and building design require detailed information on effects of a changing climate. To simulate thermal building performance appropriate data are required as "standardized weather files". But as historic weather records cannot be used to model building performance for future climate, synthetic "future weather" data are necessary. Here we present the steps to derive such data for the urban development project "Seestadt Aspern" in Vienna. We start with regional climate simulations with 10x10 km grid spacing, where hourly data for years of current and future climate have been extracted for the Aspern area. Micro-scale simulations at 5m-resolution have been carried out to consider local influences on urban micro-climate, taking regional simulation results as framework condition. As micro-simulation results are delivered only for single days, transfer functions have been developed to generate synthetic weather records, turning hourly regional climate simulation results into local climate characteristics.
\end{abstract}

Keywords: future climate, urban climate, regional climate simulation, microclimate simulation, transfer function, synthetic weather records, Seestadt Aspern, Vienna.

\section{Introduction}

Climate conditions in urban environments - today and in the future - may differ distinctively from general climate conditions, depending on certain local properties which have effects on the urban microclimate - e.g. street orientation, building height and orientation, open space distribution and surface properties, either influencing irradiance, reflection and absorption, which accelerates heating, and influence shading, ventilation and evaporation, which supports cooling.

The "Seestadt Aspern" is the test case to examine the approach providing information on the expected future climate conditions. The Aspern area is a former airfield in the East of Vienna, which shall be developed as a new urban sub-centre in the coming years, providing a mix of residential, commercial and recreational areas for 20,000 inhabitants and 26,000 employees [3]. Fig. 1 shows the general layout as planned by Tovard Architects \& Planners. Sustainability criteria are a key issue to ensure high levels of energy efficiency for buildings, as well as the general adaptability of buildings and open space to a changing climate [2]. 


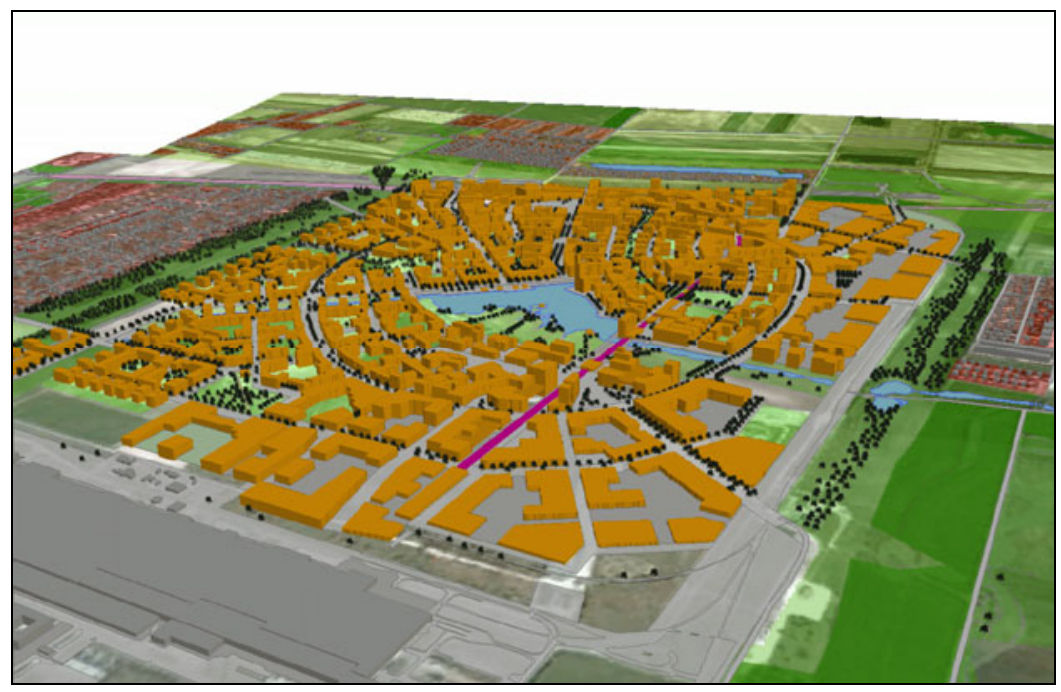

Fig. 1. The planned Aspern development, viewing north (Rendering: AIT)

Two different kinds of climate simulations are applied to provide the data for building performance simulation.

The first input comes from regional climate simulations. Regional climate model results are extracted from AIT's reclip:century project [5] applying COSMO CLM, a numerical regional climate model (RCM) delivering data on atmospheric dynamics for a century for the Greater Alpine Region with $10 \mathrm{~km}$ grid-spacing as best possible spatial resolution. Urban microclimate simulations are the second input for the Aspern area. These are modelled applying ENVI-met 3.0 - a numerical model which calculates atmospheric dynamics at city block level, considering the influence of block layout and open space pattern on irradiance, ventilation, heat flux, heat storage, humidity and transpiration etc., based on the fundamental laws of fluid dynamics and thermodynamics [1].

While regional climate simulations can be carried out for years, with a rather coarse resolution, the local climate simulations are conducted with a resolution of centimetres to meters, but only for single days. To deliver synthetic future weather records for years on an hourly basis, it is necessary to transfer the regional climate simulation results to micro-climate conditions with the help of the micro-scale simulations. This will be carried out for selected receptor points inside the Aspern area considering specific urban environment characteristics, leading to a specific microclimate which deviates distinctly from regional climate characteristics as simulated for the more rural east of Vienna.

To estimate the local deviations for the certain receptor points, transfer functions for these locations must be generated with the help of the microclimate simulation results, calculated for typical reference days. The applied weather records for building performance simulations contain temperature, wind speed and direction, solar radiation and humidity. While (horizontal) solar radiation and humidity show no or little changes within such small distances as observed in the Aspern region, temperature 
and wind characteristics data have to be transferred from regional scale to urban micro-scale to show the potential microclimate.

\section{Applied Regional Climate Simulations}

A broad variety of climate simulations, following different assumptions, have been carried out by various institutions. As we need data with a high resolution and with hourly intervals we use our own simulations. AIT's reclip:century simulations, applied here, have been carried out with the COSMO CLM regional climate model, delivering data with the best available spatial resolution $(10 \times 10 \mathrm{~km}$ grid spacing) for the entire Greater Alpine Area [5]. The simulations have been carried out for the years 1961-2050 using ERA40 global climate re-analysis data as forcing for hindcast runs and 2 global climate simulations runs (GCMs) of current climate and of future climate using ECHAM5- and HADCM3-GCM results as forcing data based on two IPCC SRES greenhouse gas scenarios (A1B, B2) [4].

The current results have been compared, e.g. regarding temperature variation, in order to examine effects of RCM forcing from different GCMs and from different SRES scenarios. Within the decades till 2050 there are no significant differences between the examined SRES scenarios. The two RCM results based on A1B forcing show also nearly the same annual mean temperatures, with some deviations during the seasons.

\subsection{Uncertainty Assessment of Regional Climate Simulations}

Modelling climate dynamics at regional scale let expect some uncertainties. To explore the uncertainty range climate scenarios have been carried out for current climate to compare the results with measurements. Regional climate simulations have been extracted from control runs for 3 current climate years (1998-2000) and compared with monitoring data. The following Fig. 2 shows this uncertainty exploration by comparing model results for climate model's raster cells where eastern Vienna (and the Aspern area) is embedded, with observation data. As the area is rather flat, the neighbouring raster cells show quite the same simulation results. This indicates that the raster cell's model results, covering Aspern, can be compared with weather records from the monitoring site Gross-Enzersdorf (located in near distance of $3 \mathrm{~km}$ to Aspern).

In general the diagram (Fig. 2) shows a high coincidence of both data sets: the correlation coefficient $\left(\mathrm{R}^{2}=0.84\right)$ lets expect little unexplained variance of around $15 \%$ between observations and model results. As the simulation results show high coincidence with the observations it can be expected that the simulations of the future climate with increasing greenhouse gas concentrations deliver similar plausible results for the decades till 2050.

The wind speed and wind direction of model results and observations turn out to be rather similar. The diagram below (Fig. 3) depicts that the model under-estimates to some extend the number of hours with wind speed $<1.5 \mathrm{~m} / \mathrm{s}$ ( 500 hours less) und slightly over-estimates the number of hours with higher wind speed $(<3 \mathrm{~m} / \mathrm{s},<5 \mathrm{~m} / \mathrm{s}$ : 200 hours more, $<7 \mathrm{~m} / \mathrm{s}$ : 100 hours more). Such deviations can be observed in many 


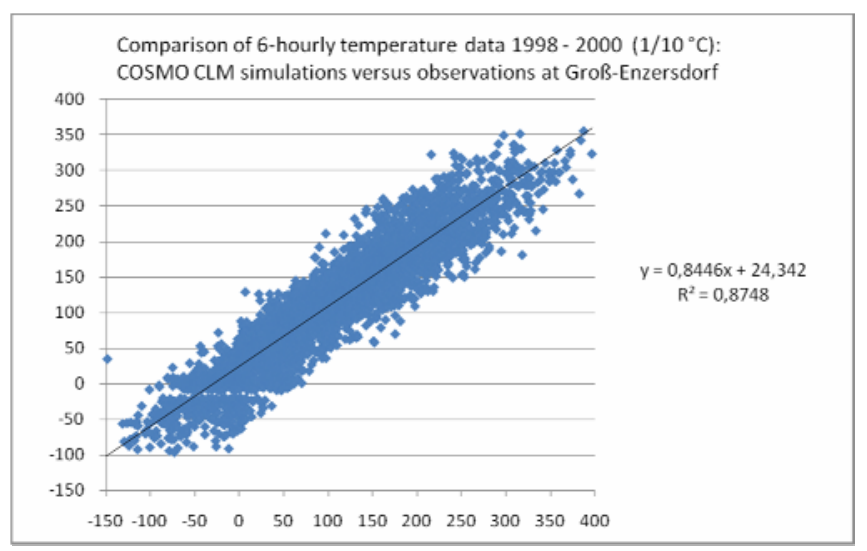

Fig. 2. Comparison of modelled and observed temperature (in $1 / 10^{\circ} \mathrm{C}$ ) in 6-hourly intervals for the years 1998-2000: COSMO-CLM simulation runs based on ERA40 forcing data for the 10x10km model cell "Vienna South-East" (Source: AIT) and Gross-Enzersdorf monitoring records (Source: ZAMG - Central Agency for Meteorology and Geodynamics, Vienna-Austria)

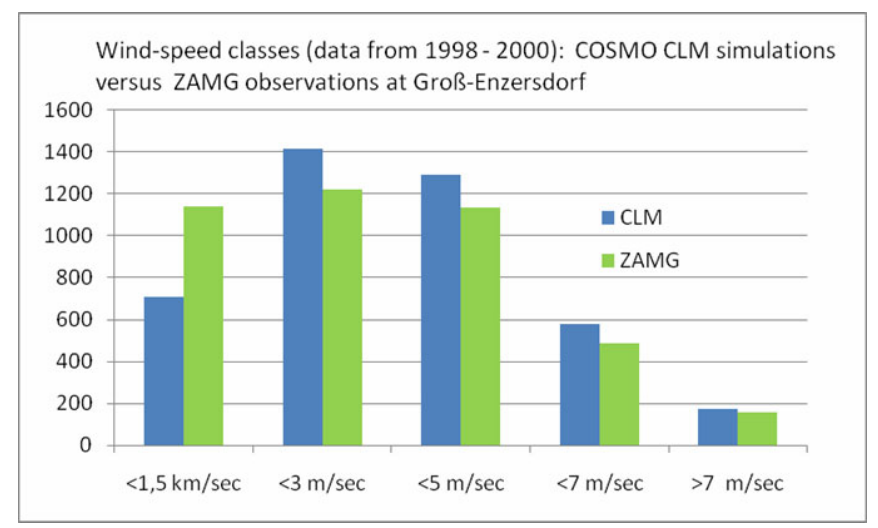

Fig. 3. Comparison of modelled and observed wind speed - hours by wind speed classes (years 1998 - 2000): COSMO-CLM simulation results for the 10x10km model cell „Vienna SouthEast"(Source: AIT) versus observations from the Gross-Enzersdorf monitoring site (Source: ZAMG)

climate simulations, because the surface roughness often turns out to be smooth, because of the climate model's coarse resolution land use model. In our simulations they are relatively small.

\subsection{Future Climate Year Selection}

Regional climate simulation results of certain reference years have to be selected, which shall serve as basis for the generation of synthetic weather records representing the local weather characteristics. Objective is to select a hot and an average year, 
which makes it necessary to examine the occurrence of hot, cool and average years of prior and coming decades. The following Fig. 4 shows the range of the highest and lowest mean temperature of the years in each decade between 1991 and 2050 for the "Vienna South-East" grid cell as carried out through the COSMO CLM simulations: the highest yearly mean temperatures increase from around $10.5^{\circ} \mathrm{C}$ to $13.3^{\circ} \mathrm{C}$, while the lowest yearly mean temperatures increase from $8.1^{\circ} \mathrm{C}$ to $10.6^{\circ} \mathrm{C}$.

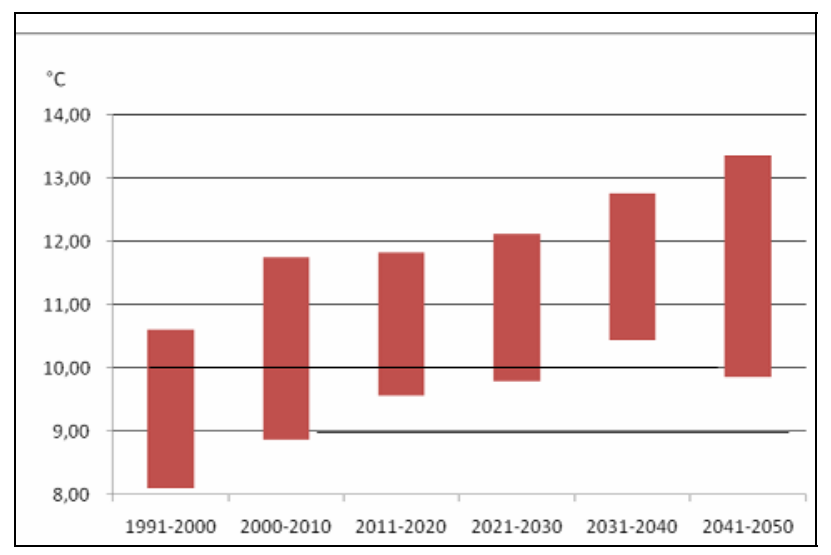

Fig. 4. Yearly temperature means of cool and hot years per decade - the range of the yearly temperature means between 1991 and 2050 for the eastern Vienna area

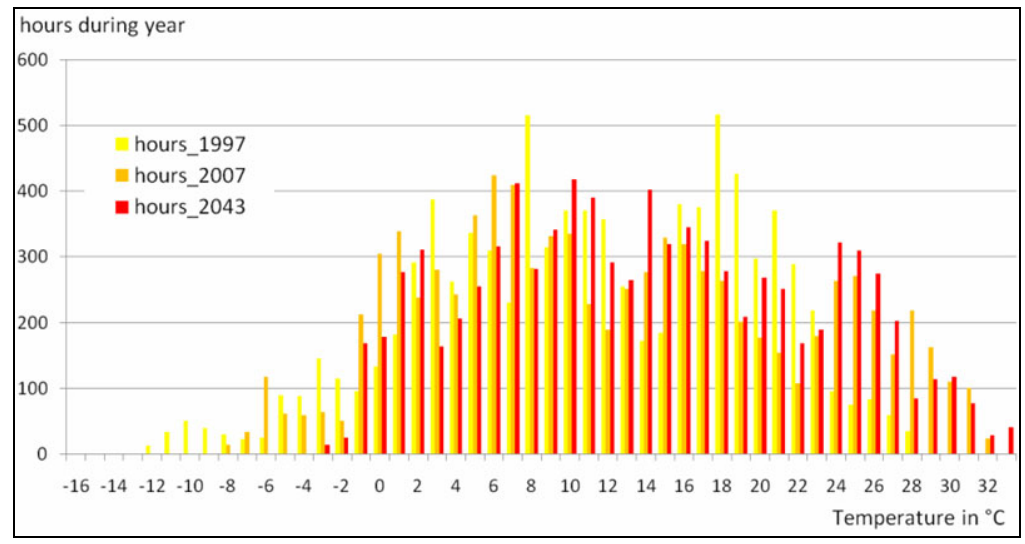

Fig. 5. Number of hours by temperature for 1997, 2007 and 2043 for the eastern Vienna area (hot reference years) (AIT)

For further simulations and investigations we take those years of the current decade and of the "last" decade 2041-2050 with highest mean temperatures as reference years to produce synthetic weather records. Fig. 5 depicts the temperature simulation results of the hottest years during the decades 1991-2000, 2001-2010 and 2041-2050 
as number of hours with identical temperature. The hottest years 2007 and 2043 will be also compared with the hottest year of the initial simulation decade - which is 1997. Distinct shifts of the number of hours by temperature can be observed: the yellow bars start with hours of $-12^{\circ} \mathrm{C}$ and range till hours of $28^{\circ} \mathrm{C}$, the orange bars of the year 2007 start with hours of $-8^{\circ} \mathrm{C}$ and range till hours of $32^{\circ} \mathrm{C}$, while the red bars (of year 2043) start with hours of $-3^{\circ} \mathrm{C}$ and range till hours of $34^{\circ} \mathrm{C}$ and above.

The shifts show the distinct changes of the temperature regime to be expected during certain episodes of the coming years which will have much effect on the local microclimate which really requires quantifying these effects with appropriate accuracy.

\section{Urban Microclimate Simulations}

The micro-simulations are carried out for the entire Aspern area with a spatial resolution of a few meters. The applied model, ENVI-met 3.0, is a micro-climate modelling tool, which is able to simulate and analyse small scale interactions between urban design and the immediate climatic surrounds, with high resolutions. The model simulates fluid dynamic and thermodynamic processes taking place at walls, roofs, ground surface, interacting with soil, plants and the atmospheric boundary conditions which deliver local atmosphere dynamics like wind flow, radiation, fluxes, temperature and humidity during one day or a few days at city block scale [1].

To conduct the simulation, the study area has to be defined with its 2D- and 3D conditions by several input data sets using identical grid spacing: building shapes and heights, as well as properties of these structures such as heat storage capacity and irradiance reflection; plant sizes and characteristics relating to shading/wind protection; surface conditions of roads and open space including tree locations, surface roughness, moisture content etc. Therefore a virtual 3D-block model is introduced to consider these effects of building-, street- or plaza layout due to different spatial characteristics like street width and orientation, building orientation and height as well as open space layout and vegetation [6]. The 3D model for the Aspern development shows a 5 and $7 \mathrm{~m}$ cell resolution as input for the ENVI-met simulations which also defines the output resolution. The 3D-model has been carried out by exploring the preliminary Master plan and the related building height concept [2].
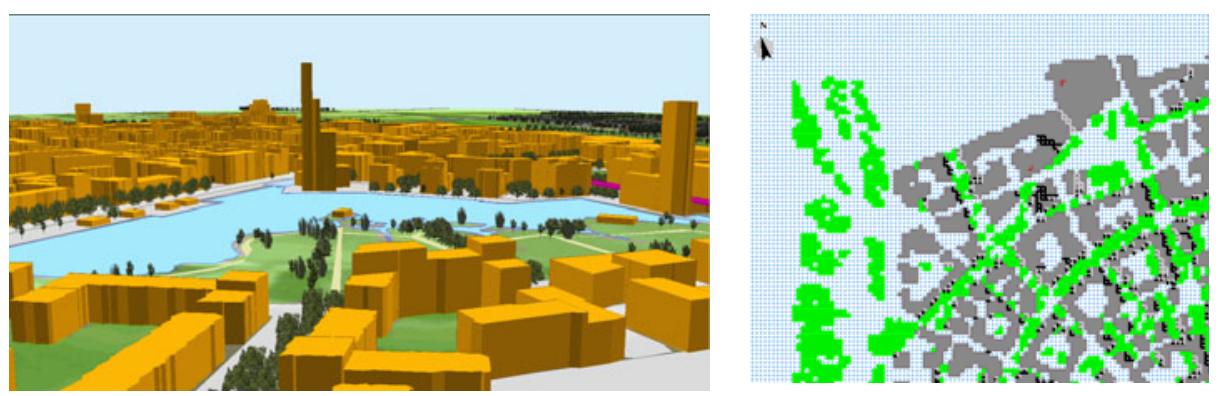

Fig. 6. Block volumes and building heights transferred into a $7 \mathrm{~m}$ resolution 3D-model compatible with ENVI-met formats. (Rendering of the central Aspern area and a detail of the ENVI-met 3D-model edit environment (AIT) 
Initial atmospheric framework conditions are integrated at the beginning of the model runs, requiring also data like geographical positioning, date and time (to calculate the solar angle), wind speed and wind direction at ground level, the initial temperature at ground level, the specific humidity at $2500 \mathrm{~m}$ and the relative humidity at ground level. Meteorological information comes from a nearby monitoring site or is derived from climate model-outputs for the grid-cells covering the study area.
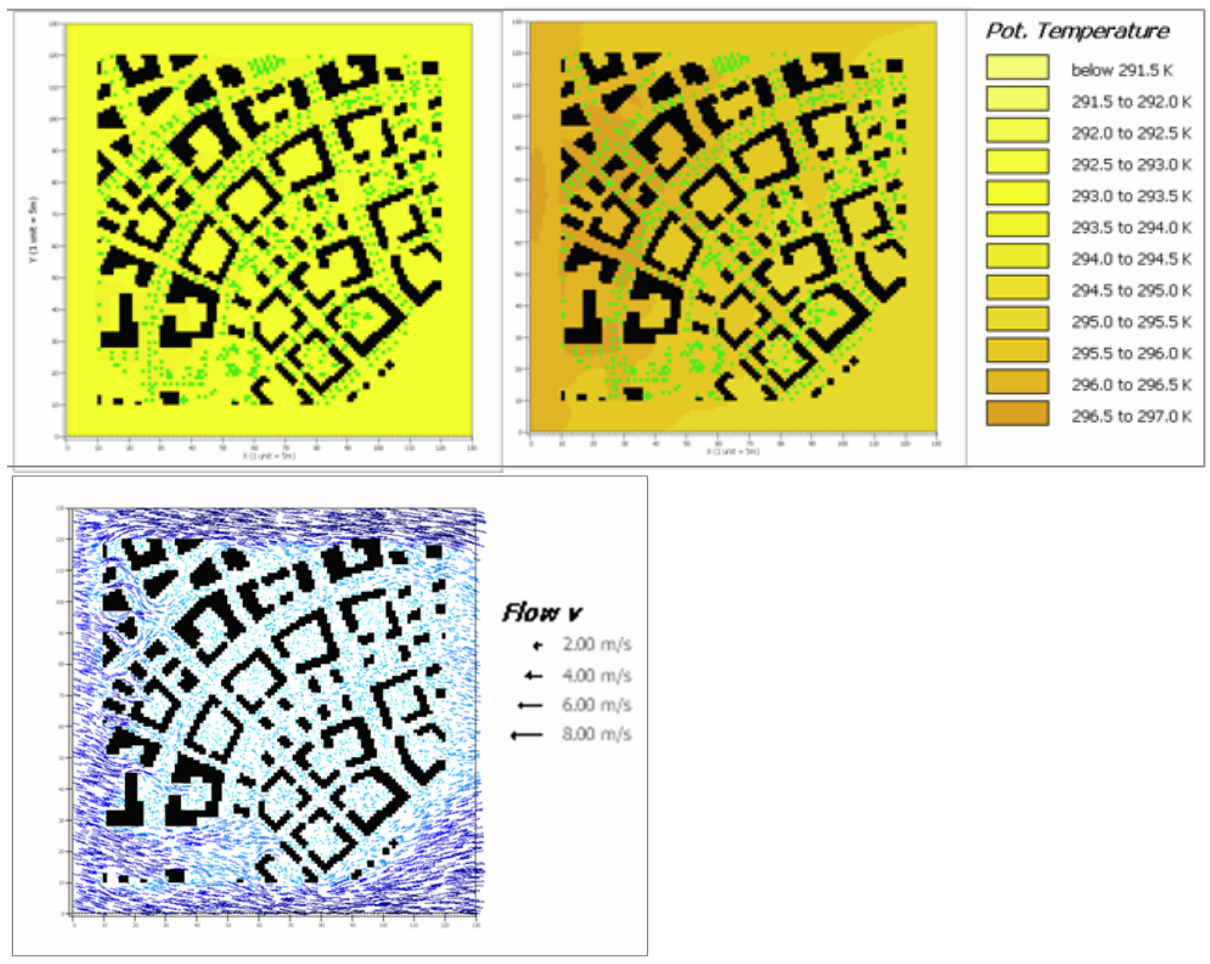

Fig. 7. Potential air temperature at $8 \mathrm{~h}$ (top-left) and $12 \mathrm{~h}$ (top-right) and initial windfield pattern (bottom) at 21st of June in the Aspern North-West quadrant (AIT)

A wide range of data is simulated by ENVI-met, and stored as 3D-fields which can be extracted and visualized for any section and direction (beside temperature indicators and wind, humidity, surface conditions, soil conditions, plant conditions and several others) [1]. Fig. 7 shows some results for a detail of the Aspern development the North-West quadrant: the increase of the potential temperature and local wind fields.

\section{Development of Transfer Functions for Temperature and Wind Characteristics}

Transfer functions calculate the deviations of the micro-scale weather conditions from the regional weather conditions at certain receptor points for selected typical weather 
characteristics. Representative spots have been selected as receptor points to generate transfer functions generally representative for the urban environment properties. The occurrence of strong local influence from building walls and corners or special open space properties has been avoided by allocating the points in some distance to the buildings.

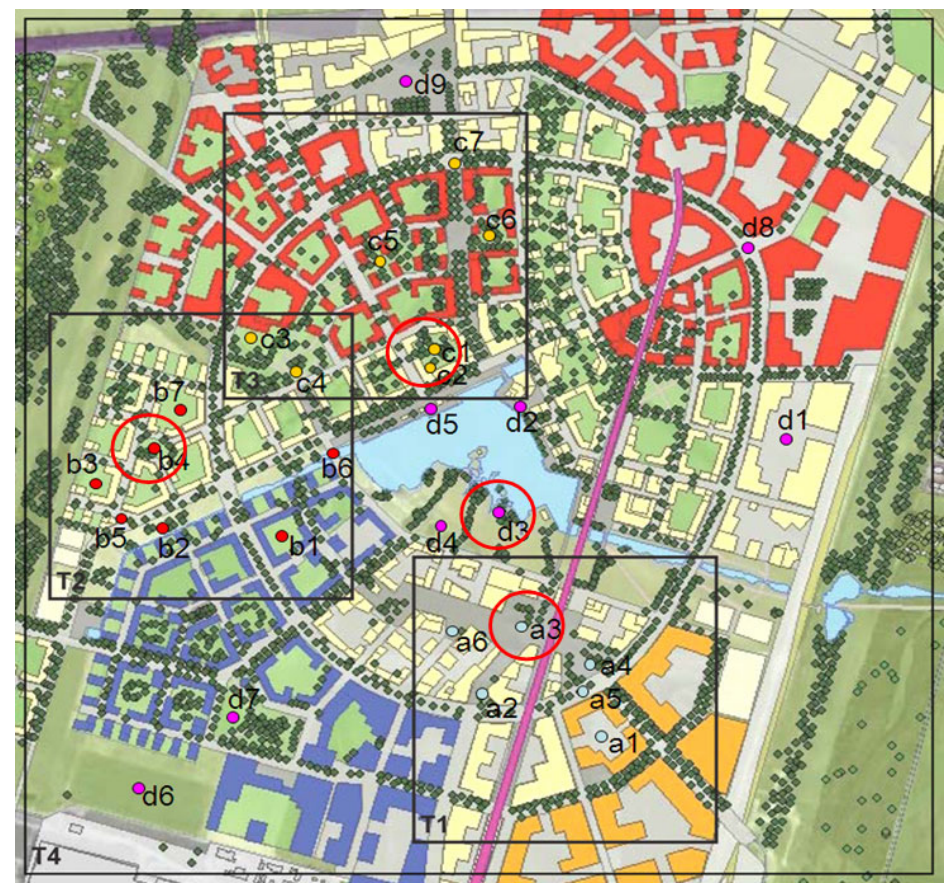

Fig. 8. Receptor points (red circles) in the selected reference areas of Aspern where transfer functions shall be applied

\subsection{Functions to Transfer Regional to Local Temperature}

To derive transfer functions to estimate local temperature starting from the regional climate simulations, the regional climate model results have to be compared with the diurnal temperature dynamics as conducted by the ENVI-met model.

The variation of the local temperatures during a day are expected to be rather high because of changes in radiation, shading, surface properties in terms of reflection and as well as in terms of soil humidity supporting evaporation and thus cooling.

Fig. 9 compares different temperature indicators as modelled for the 4 receptor points during a day - the mean radiant temperature shows the highest peaks (left diagram) - due to full sunlight exposure and additional exposure from reflections from the surface and the surrounding facades. The surface temperature (centre diagram) shows still a high variation, depending on the surface properties: humid open grassland provides some cooling which lowers the amplitude. Concrete or asphalt surfaces (the blue line of receptor point a3) operate more as heat storage. (Both two indicators 
are influenced by temporal shades which provide some cooling around $14 \mathrm{~h}$ ). The potential temperature (right diagram) excludes all effects of direct solar radiation and reflection. The amplitude seems to be too low for all receptor points.

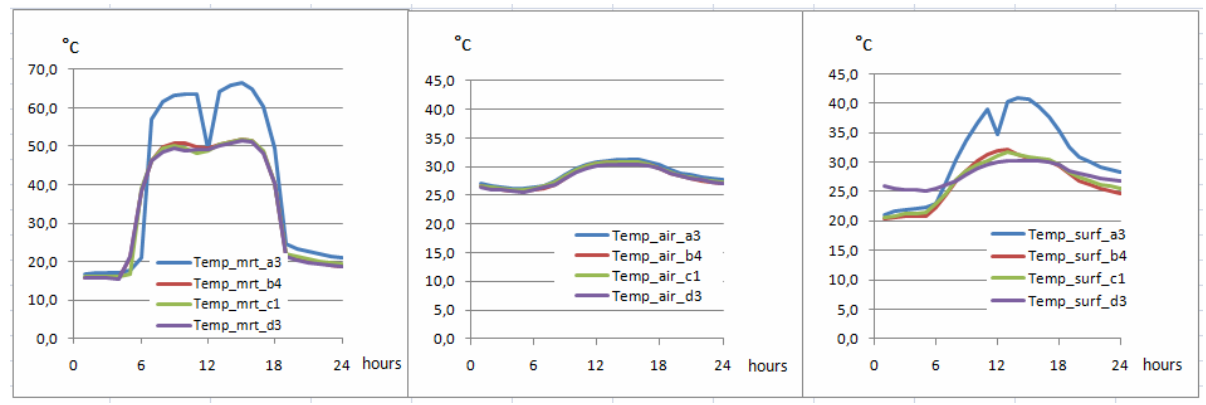

Fig. 9. Comparison of diurnal temperature dynamics (hourly data): mean radiant temperature (Temp_mrt), potential (air) temperature (Temp_air) and surface temperature (Temp_surf), for the 4 receptor points a3,b4,c1,d3 (as shown in Fig. 8)

As no actual air temperature is delivered by the model, the actual temperature (as observed by weather monitoring equipment) is estimated by taking the potential temperature and applying reverse equations to calculate the potential temperature out of relative humidity, atmospheric pressure and the gas constant.

Further the hourly temperatures of the 10 peak days of the year 2043 have to be extracted from the regional climate simulations. (Here shown for the "open space" receptor point $\mathrm{d} 3$ near the lake shore). Fig. 10 compares the temperature dynamics of these 10 hot days for receptor point $\mathrm{d} 3$.



Fig. 10. Diurnal temperature-variation extracted from the regional climate simulations for peak days in June and July 2043

Finally the diurnal variation of the actual temperature at the receptor points will be compared with the day dynamics of the regional climate simulations. The basic assumptions are: 
- The diurnal temperature variations of the regional climate simulations describe the daily weather around Aspern.

- The local temperature variations for the 4 receptor points in Aspern as derived by ENVI-met (with $7 \mathrm{~m}$ resolution) for certain days take the regional climate simulation results as input, simulating the local effects, which occur at these specific days (certain temperature, wind, radiation, cloud cover), considering the local block and street layout and the open space properties.

These day patterns and the differences between the regional climate and microclimate simulations are the reference to develop transfer functions for the receptor points to achieve daily weather records out for the regional simulation results. Depending on the climate situation, the transfer function sets are modified through different factors. The factors for receptor point $\mathrm{i}$ for one day will be derived in the following way:

$$
F\left(h, \operatorname{tg}_{y}, i\right)=\left(\operatorname{Tr}\left(d_{x}, h\right) / T p(h, i)+\ldots+T\left(d_{x+1}, h, r\right) /(T p(h, i)) / n\right.
$$

where:

$F\left(h, t_{y}, i\right)=$ factor for hour $h$ for day-type y at receptor point $\mathrm{i}$

$\operatorname{Tr}\left(d_{x}, h\right)=$ regional temperature for hour $\mathrm{h}$ at day $d_{x} ; x=\{a, \ldots, n\}$,

$n=$ number of selected days for averaging the hourly factors

$T p(h, i)=$ receptor point temperature for hour $\mathrm{h}$; at receptor point $\mathrm{i}$

The local day- and hour-specific temperature at the receptor point - $T p(d x, h, i)$ - is carried out by:

$$
\operatorname{Tp}(d x, h, i)=\operatorname{Tr}(d x, h) * F(h, \operatorname{tg} y, i)
$$

where

factor set $F()$ is selected, depending on the day type and the initial regional temperature at the respective day. The number of alternative day types depends on the intensity of differences between these types.

The diagrams in Fig. 11 show the results for all 4 receptor points for different summer days in the year 2043. The dotted coloured lines show the regional temperature variation - on example of a warm and a really hot day. The dashed black line shows the local temperature as calculated by ENVI-met. The solid coloured lines show the temperature patterns as derived by the transfer functions. These lines reflect both temperature influences: those from the regional model and those from the microsimulation (see the location specific variations in shape!).

\subsection{Functions to Transfer Regional to Local Wind Characteristics}

The local wind direction change depends on the urban fabric characteristics of the respective receptor point and the initial regional wind speed. The intensity of wind speed change depends again on the urban fabric characteristics. Wind transferfunctions will be derived through comparison of the regional wind characteristics with the local ones derived by ENVI-met and extracted for the respective receptor points.

This has been carried out by simulating wind fields with predefined wind speed and wind direction taking 8 major wind direction classes. Transfer functions are estimated with the help of non-linear curve fitting models (log-, exponential-, polynomic 




Fig. 11. Temperature-variation for two different summer peak days in June und July 2043 (for all 4 receptor points / areas)

functions) to calculate local wind-speed decline, depending on initial (regional) wind direction and regional wind-speeds, and to calculate the local wind direction deviations from the regional wind directions.

The following diagrams in Fig. 12 show the wind speed decline for one receptor point as example for two wind directions. The details are not relevant to describe the approach, but generally wind speed decline is different for different wind directions with respect to the urban fabric characteristics which serve - more or less - as barrier.

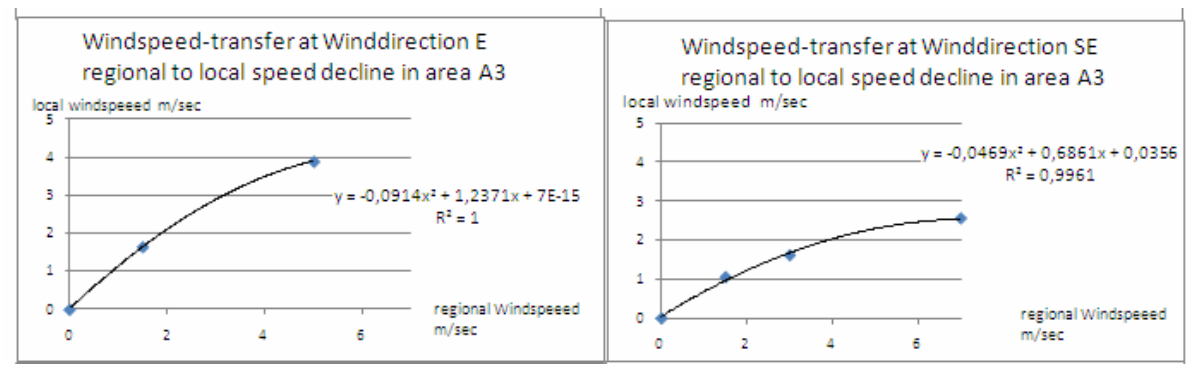

Fig. 12. Transfer-functions for local wind speed decline by initial regional wind speeds as example for two main wind directions at receptor point a3

Change of wind directions is different depending on the receptor point location (Fig. 13 presented for one point for 2 wind directions). The developed transfer functions do not deliver new local wind directions in degrees but deliver an either positive 
or negative deviation of the local wind direction from the regional one, to avoid < $360^{\circ} />0^{\circ}$ transition-problems.

In general the wind direction deviations are rather small at the selected receptor points (which was expected because of the selection of receptor points in undisturbed environment). The highest deviations reach less than $10 \%$ which is 36 degrees. Often they are within a range of $+/-2 \%$ which is less than 10 degrees. Certainly the local wind direction deviations tend to diminish with declining (regional) wind speed.

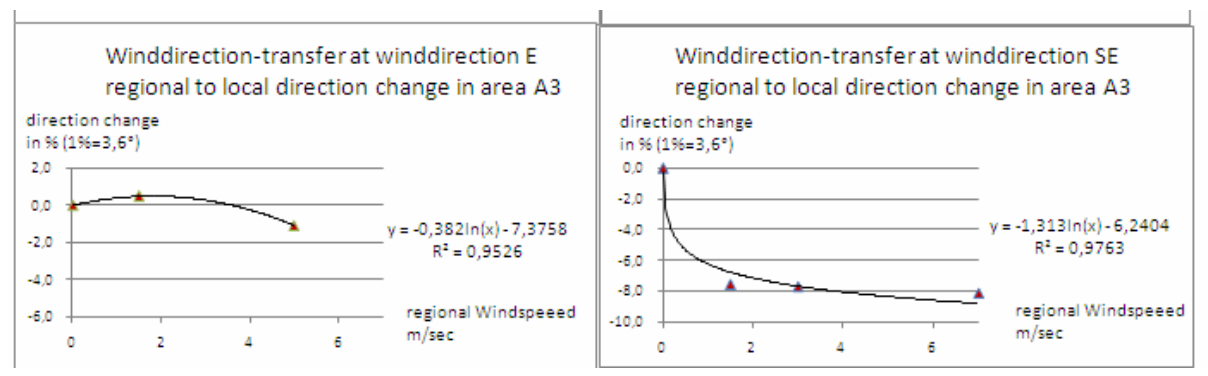

Fig. 13. Transfer-functions for local wind direction deviation by (initial) regional wind speeds as example for two main wind directions at receptor point a3

\section{Conclusions}

The transfer functions turned out to be applicable to generate hourly data of temperature and wind characteristics for synthetic weather records for future climate which have been applied to simulate thermal building performance and to estimate the energy demand for different settings building properties, considering different surface conditions, different open space layout and different building orientations [7]. Fig. 14 compares the energy demand for heating and cooling for a virtual test building to be erected at one of the receptor points in the Aspern area.

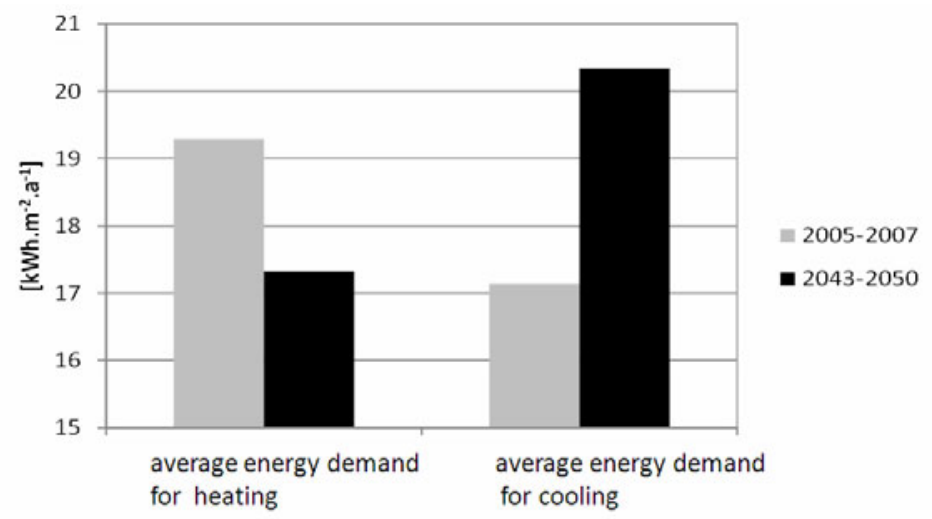

Fig. 14. Estimated changes in energy demand for heating and cooling for different climate situations for a defined building concept -an application example applying the synthetic weather records described above. (Source: Ohrehounig et al. [7]) 
In the future these methods will be applied to different urban fabric settings in order to explore the effects of these settings on micro-climate conditions systematically. It is finally planned to carry out a set of synthetic weather records for future climate for certain representative urban environments.

\section{References}

1. Bruse, M., Feer, H.: Simulating surface-air-plant interactions inside urban environments with a three dimensional numerical model. Env. Modelling and Software 13, 383-384 (1998)

2. City of Vienna: Aspern Airfield Masterplan (English, German), by Tovard Architects \& Planners AB; Magistrat der Stadt Wien, 1082 Wien (2008)

3. Hageneder, C., Hinterkörner, P.: Aspern, Die Seestadt Wiens - nachhaltige Stadtentwicklung. In: Conference Proceedings, CORP 2010, Wien, pp. 989-994 (2010)

4. IPCC: Climate Change: The Physical Science Basis. Final Report Working Group 1, Intergovernmental Panel on Climate Change, Assessment Report 4, Geneva, Switzerland (2007)

5. Loibl, W., et al.: Reclip:century - a project conducting 21 st century regional climate simulation runs focussing on the Greater Alpine Region. EGU General Assembly, Vienna 2010. Geophysical Research Abstracts 12 (2010)

6. Loibl, W., Jäger, A., Knoflacher, M., Köstl, M., Züger, J.: Urban Streetscapes responding to changing climate conditions - Effects of street layout on Thermal Exposure. In: Proceedings BAUSIM 2010, Technical University Vienna (2010)

7. Orehounig, K., Mahdavi, A., Hagen, K., Trimmel, H., Stiles, R., Knoflacher, M., Loibl, W.: Maßnahmenkatalog für Bauträgerwettbewerbe betreffend Oberflächengestaltung von Fassaden und Freiräumen. TU Wien (2011) 